\title{
Modulation of bleomycin-induced lung fibrosis by serotonin receptor antagonists
} in mice

\author{
A. Fabre*,\#, J. Marchal-Sommé*, S. Marchand-Adam*, , C. Quesnel*, R. Borie*, \\ M. Dehoux**+, C. Ruffié*, J. Callebert ${ }^{\S}$, J-M. Launay ${ }^{\S}$, D. Hénin ${ }^{\#}$, \\ P. Soler* and B. Crestani ${ }^{\star}, \oplus$
}

ABSTRACT: Serotonin (5-hydroxytryptamine; 5-HT) is known to increase proliferation and collagen synthesis by fibroblasts. Two receptor subtypes, 5-HT2A and 5-HT2B, have been shown to play the most important roles in the lung.

In the present study, the role of serotonin in lung fibrosis was investigated using the bleomycin mouse model.

Serotonin concentrations in lung homogenates increased significantly over the time course of bleomycin-induced fibrosis, with a maximum at day seven. The expression of serotonin receptors 5-HT2A and 5-HT2B increased in the lung after bleomycin treatment, as assessed by PCR, specific binding and immunohistochemistry. Blockage of 5-HT2A receptors by ketanserin and 5-HT2B receptors by SB215505 reduced bleomycin-induced lung fibrosis, as demonstrated by reduced lung collagen content and reduced procollagen 1 and procollagen 3 mRNA expression. Serotonin antagonists promoted an antifibrotic environment by decreasing the lung mRNA levels of transforming growth factor- $\beta 1$, connective growth factor and plasminogen activator inhibitor-1 mRNA, but had minimal effects on lung inflammation as assessed by bronchoalveolar lavage cytology analysis. Interestingly, the 5-HT2B receptor was strongly expressed by fibroblasts in the fibroblastic foci in human idiopathic pulmonary fibrosis samples.

In conclusion, the present study showed involvement of serotonin in the pathophysiology of bleomycin-induced lung fibrosis in mice and identified it as a potential therapeutic target in lung fibrotic disorders.

KEYWORDS: Bleomycin, lung fibrosis, receptors, serotonin

$\mathbf{P}$ ulmonary fibrosis is a chronic interstitial lung disease that responds poorly to available medical therapies and carries a potentially fatal prognosis. The course is usually indolent but inexorable. Most patients die of progressive respiratory failure within $3-5 \mathrm{yrs}$ of the onset of symptoms. Current therapies are of unproven benefit [1] and a huge effort is being developed worldwide to identify new therapies.

Serotonin (5-hydroxytryptamine; 5-HT), is a vasoactive peptide synthesised from tryptophan by enterochromaffin cells in the gut and by endothelial cells $[2,3]$. Very low levels of circulating free serotonin are present in the blood as most serotonin is pooled in the platelets. In physiological conditions, the lung is exposed to low levels of circulating serotonin. In pathological conditions, release of serotonin stored by platelets and endothelial cells may increase the serotonin concentration both locally and in the circulation. To date, 14 receptors for serotonin have been identified [4]. Most are G-coupled receptors, and 5-HT2A and 5-HT2B receptor subtypes have been shown to play the most important roles in the lung, where serotonin participates in the control of vasoreactivity and bronchoreactivity $[5,6]$.

Recent in vitro studies have demonstrated the mitogenic and profibrotic role of serotonin on different types of mesenchymal cells. Serotonin enhanced the proliferation of fibroblasts cultured from pulmonary arteries from hypoxic rats, and its effect was co-mitogenic with the addition of serum [7].

\section{AFFILIATIONS}

*Faculté de Médecine Denis Diderot, INSERM Unit 700, Université Paris 7 , \#Service d'Anatomie Pathologique, "Service de Pneumologie,

+Laboratoire de Biochimie A, Hôpital Bichat, Assistance Publique Hôpitaux de Paris, and

${ }^{\S}$ Service de Biochimie, Hôpital

Lariboisière, Paris, France.

\section{CORRESPONDENCE}

B. Crestani, INSERM Unit 700,

Faculté de Médecine Paris 7 Denis

Diderot, 16 rue Henri Huchard,

75018 Paris, France.

Fax: 33140258818

E-mail: bruno.crestani@bch.aphp.fr

Received:

September 262007

Accepted after revision:

February 252008

SUPPORT STATEMENT

A. Fabre was supported by a grant from the Association Française pour la Recherche Thérapeutique (Paris, France) and the Collège des

Professeurs de Pneumologie (Paris). S. Marchand-Adam received the Prix Mariane Josso and C. Quesnel received a grant from the Fondation pour la Recherche Médicale (Paris). P. Soler was the recipient of a Contrat d'Interface Inserm from the Assistance Publique Hôpitaux de Paris (Paris)

STATEMENT OF INTEREST A statement of interest for this study can be found at www.erj.ersjournals.com/misc/ statements.shtml

Online ISSN 1399-3003 
Outside the lung, serotonin has been shown to play a critical role in modulating the characteristic phenotypic changes of the hepatic stellate cells in response to liver injury [8]. In renal mesangial cells, serotonin potently activated extracellular signalregulated kinase, induced transforming growth factor (TGF)- $\beta 1$ and increased cell proliferation via the 5-HT2A receptor [9]. Similarly, the addition of serotonin to aortic valve interstitial cells induced increased collagen synthesis, as well as TGF- $\beta 1 \mathrm{mRNA}$ expression and activity [10], through the activation of the 5-HT2A receptor [11]. Stimulation of the 5-HT2B receptor may also contribute to the remodelling properties of serotonin, as demonstrated in a mouse model of pulmonary hypertension [12]. Interestingly, the 5-HT2B receptor has been shown to regulate cell cycle progression together with the platelet-derived growth factor receptor pathway [12].

In view of these data, the current authors hypothesised that serotonin could play a role in the pathophysiology of lung fibrosis through its pro-proliferative and profibrotic properties, via its 5-HT2A and 5-HT2B receptors. The aims of the present study were as follows: 1) to characterise the expression of serotonin receptors in the murine and human fibrotic lung; 2) to determine whether modulation of the serotonin pathway, using specific pharmacological antagonists of 5-HT2A and 5-HT2B receptors, could attenuate the development of lung fibrosis and alter bronchoalveolar lavage fluid (BALF) inflammatory components in the murine model of bleomycininduced lung fibrosis; and 3) to characterise the pathways involved in this effect.

\section{MATERIALS AND METHODS Bleomycin lung fibrosis}

All experiments were performed using adult male C57BL/6 mice, aged 6-7 weeks and weighing 20-24 g (Elevage Janvier, Le Genest Saint Isle, France). The experiments were performed according to INSERM (Paris, France) guidelines that complied with national and international regulations. The mice had access to water and food ad libitum, prior to and during pharmacological treatments.

On day zero, the mice were anaesthetised intramuscularly with ketamine hydrochloride $\left(45 \mathrm{mg} \cdot \mathrm{kg}^{-1}\right)$ and $2 \%$ xylazine $\left(9 \mathrm{mg} \cdot \mathrm{kg}^{-1}\right)$ and then were administered a single $80 \mu \mathrm{g}$ dose of intratracheal bleomycin hydrochloride (Bleomycine Bellon; Aventis, Paris, France) suspended in $50 \mu \mathrm{L} 0.9 \%$ sterile saline. Naïve mice were used as controls.

A group of animals was used for the evaluation of serotonin concentrations and serotonin receptor expression in the lung over the time course of lung fibrosis development. On days three, seven and 14 post-bleomycin, animals were killed with i.p. ketamine $\left(60 \mathrm{mg} \cdot \mathrm{kg}^{-1}\right)$ and xylazine $\left(8 \mathrm{mg} \cdot \mathrm{kg}^{-1}\right)$. To minimise platelet activation, mice received $50 \mathrm{IU}$ of heparin intraperitoneally, $15 \mathrm{~min}$ prior to sacrifice.

A second group of animals was used to assess the effect of 5-HT2A and 5-HT2B receptor antagonists in the bleomycin mouse model. Mice were administered intratracheal bleomycin on day zero, then treated with a daily i.p. injection of $2 \mathrm{mg} \cdot \mathrm{kg}^{-1} \cdot$ day $^{-1}$ ketanserin, a specific antagonist of the 5-HT2A receptor (Sigma-Aldrich, Lyon, France), diluted in $200 \mu \mathrm{L}$ sterile saline, or $0.5 \mathrm{mg} \cdot \mathrm{kg}^{-1} \cdot$ day $^{-1} \mathrm{SB} 215505$, a specific antagonist of the 5-HT2B receptor (kindly provided by GlaxoSmithKline,
Stevenage, UK), diluted in $200 \mu \mathrm{L}$ sterile saline. Both these molecules were lipopolysaccharide free. Mice were treated from day 0-13. Control animals received the vehicle only (dimethylsulphoxide at 1:1000 dilution in $0.9 \% \mathrm{NaCl}$ ). For bronchoalveolar lavage (BAL) and histological studies, mice were administered either bleomycin or the same volume of saline intratracheally, and then treated with ketanserin and SB215505 over the 14-day period. Animals were sacrificed on days three, seven and 14.

\section{Serotonin assay in lung homogenates}

The caudate and apical lobes of the right lung were snapfrozen for serotonin dosage. Lungs were homogenised in icecold $0.1 \mathrm{M}$ acetic acid containing $10 \mu \mathrm{M}$ sodium metabisulphite, $10 \mu \mathrm{M}$ EDTA and $10 \mu \mathrm{M}$ ascorbic acid. After centrifugation for $15 \mathrm{~min}$ at $17,500 \times g$ at $4^{\circ} \mathrm{C}$, the supernatant was passed through a $10-\mathrm{kDa}$ filter (Nanosep ${ }^{\circledR} 10 \mathrm{kDa}$; Pall Life Sciences, VWR, Fontenay-sous-Bois, France) by centrifugation for $30 \mathrm{~min}$ at $12,500 \times g$ at $4{ }^{\circ} \mathrm{C}$. An aliquot of $20 \mu \mathrm{L}$ was analysed for serotonin by isocratic elution and electrochemical detection on a serial electrode array of coulometric flow-through graphite electrodes (CoulArray®; ESA, EUROSEP Instruments, Cergy St Christophe, France). Serotonin was then identified based on retention time as well as electrochemical behaviour across the arrays. The analysis, data reduction and peak identification were fully automated. The results were expressed in pmol for the caudate and apical lobes combined.

\section{5-HT2A and 5-HT2B receptor binding in lung tissue}

Quantification of the 5-HT2A and 5-HT2B receptors in lung tissue was performed by binding experiments using selective tritiated radioligands: MDL100907 at $745 \mathrm{GBq} \cdot \mathrm{mmol}^{-1}$ for the 5-HT2A receptor, and LY266097 at $925 \mathrm{GBq} \cdot \mathrm{mmol}^{-1}$ for the 5-HT2B receptor; both provided by J. Würch (Roche, Basel, Switzerland). Briefly, cell membranes were prepared by four cycles of homogenisation and centrifugation $(48,000 \times g$ for $15 \mathrm{~min}$ ) at $4^{\circ} \mathrm{C}$. Assays were established to achieve steady-state conditions and to optimise specific bindings. Membrane protein samples of $50 \mu \mathrm{g}$ were incubated with $1 \mathrm{nM}$ ${ }^{3} \mathrm{H}-$ MDL100907 or ${ }^{3} \mathrm{H}-\mathrm{L} Y 266097$ at $4{ }^{\circ} \mathrm{C}$ for $60 \mathrm{~min}$. Nonspecific bindings were determined using $1 \mu \mathrm{M}$ ketanserin for the 5-HT2A receptor and RS127445 for the 5-HT2B receptor (provided by M. McNamara, Syntex, Palo Alto, CA, USA). Assays were terminated by vacuum filtration through glass fibre filtres (GF/B grade) that had been pretreated with $0.1 \%$ polyethyleneimine. Total and bound radioactivities were determined by liquid scintillation counting. Specific binding $>80 \%$ was achieved in these assays.

\section{BALF}

BALF was obtained by cannulating the trachea and washing the lungs four times with $250 \mu \mathrm{L}$ aliquots of sterile saline on day 14. Total cell counts were made using a glass Malassez counter. Differential cell counts were estimated from cytospin preparations by counting 200 cells stained with Diff-Quick (Dade Behring GmbH, Eschborn, Germany). BALF supernatant was then centrifuged, aliquoted with aprotinin and stored at $-20^{\circ} \mathrm{C}$ until analysis.

\section{TGF- $\beta 1$ assay}

Activated TGF- $\beta 1$ concentrations in BALF were determined by ELISA with Quantikine ${ }^{\circledR}$ mouse/rat/porcine TGF- $\beta 1$ (R\&D 


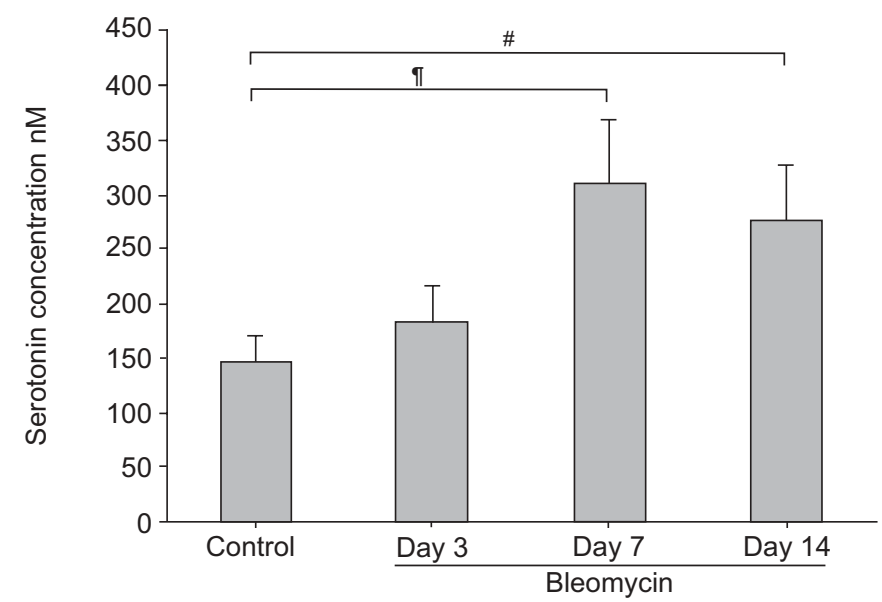

FIGURE 1. Serotonin concentration in lung homogenates from the right apical and cardiac lobes of the right lung, at days three, seven and 14 post-bleomycin administration and in controls (naiive mice). Serotonin was increased from day three, with a maximum at day seven, and remained increased at day 14 compared with controls. At each time-point, three to five animals were used. Error bars indicate SEM. ${ }^{*}: p=0.04 ; ": p=0.008$.

Systems Europe, Lille, France) according to the manufacturer's instructions.

\section{Determination of lung inositol triphosphate levels}

In order to check that ketanserin and SB215505 (at the doses of $2 \mathrm{mg} \cdot \mathrm{kg}^{-1} \cdot \mathrm{day}^{-1}$ and $0.5 \mathrm{mg} \cdot \mathrm{kg}^{-1} \cdot \mathrm{day}^{-1}$, respectively) were active in the lung in vivo, lung inositol 1,4,5-triphosphate $\left(\mathrm{IP}_{3}\right)$ concentrations were measured in mice treated with ketanserin and SB215505 at increasing doses. Daily i.p. injections of ketanserin or SB215505 were given to five mice in each group. On day seven, mice were killed and their lungs sampled and homogenised. 2,5-Dimethoxy-4-iodoamphetamine was added at $1 \mu \mathrm{M}$ to the homogenate. After centrifugation, $\mathrm{IP}_{3}$ was quantified in the supernatant with use of a radioimmunoassay (Biotrak Assay; Amersham, GE Healthcare Life Sciences, Saclay, France) as previously described [6, 13]. Each dosage was repeated three times. The results were expressed as $\mathrm{pmol} \cdot \mathrm{mg}^{-1}$ protein.

\section{Lung morphology}

The left lung was fixed by inflation with a buffered $4 \%$ paraformaldehyde solution for $24 \mathrm{~h}$ then embedded in paraffin and stained with haematoxylin-phloxin-saffron, Masson's trichrome (MT) and Picrosirius (PS).

\section{Immunohistochemistry}

Paraformaldehyde-fixed, paraffin-embedded, 3- $\mu$ m sections of mouse left lung were deparaffinised in xylene and alcohols, and pretreated in citrate buffer $\mathrm{pH} 6$ for 45 min for antigen retrieval. Serial sections were pretreated with peroxidase blocking reagent $\left(\mathrm{ARK}^{\mathrm{TM}}\right.$ detection kit; Dako, Trappes, France) and then incubated with anti-5-HT2A- or anti5-HT2B-receptor antibodies (clones G186-1117 and A72-1, respectively; BD, Le Pont-de-Claix, France) for $15 \mathrm{~min}$ at room temperature. Staining was revealed by diaminobenzidine using the $\mathrm{ARK}^{\mathrm{TM}}$ detection kit. All immunostainings were performed at the same time in a given animal to limit
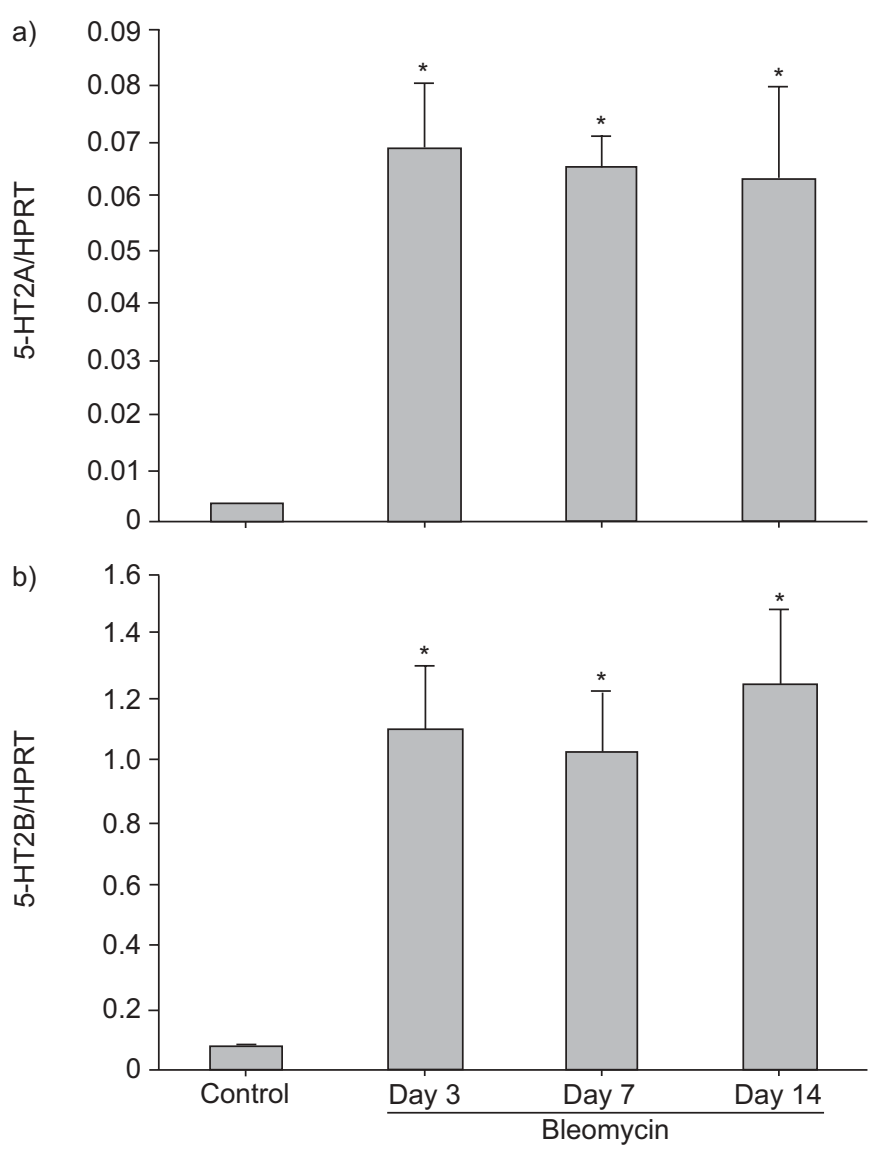

FIGURE 2. Expression of a) serotonin (5-hydroxytryptamine; 5-HT)2A and b) 5HT2B receptor mRNA in bleomycin-induced lung fibrosis. Results are expressed relative to the housekeeping gene hypoxanthine phosphoribosyltransferase (HPRT). Note the increased expression of both receptors in the bleomycin-treated lung from day three compared with controls (naïve mice), which was sustained significantly over time. At each time-point, three to five animals were used. Error bars indicate SEM. ${ }^{*}: p<0.05$.

variability in levels of expression. Negative controls were incubated with mouse immunoglobulin G1 (Dako).

\section{Total soluble collagen assay}

Frozen unlavaged right lung was homogenised in $1 \mathrm{~mL}$ of icecold sample buffer $(10 \mathrm{mM}$ Tris-HCl-buffered solution ( $\mathrm{pH}$ 7.4) containing $2 \mathrm{M} \mathrm{NaCl}, 1 \mathrm{mM}$ phenylmethylsulphonyl fluoride, $1 \mathrm{mM}$ EDTA and $0.01 \%$ Tween 20). The lung homogenates were shaken for $24 \mathrm{~h}$ at $4{ }^{\circ} \mathrm{C}$ and centrifuged at $12,000 \times g$ for $60 \mathrm{~min}$ to remove debris. The clear upper supernatant fluid $(250 \mu \mathrm{L})$ was used for the Sircol ${ }^{\mathrm{TM}}$ assay (Biocolor Ltd, Carrickfergus, UK) according to manufacturer's instructions and optical density readings were made at $550 \mathrm{~nm}$. Results were expressed as $\mu \mathrm{g}$ collagen per right lung.

\section{Extraction of mRNA, cDNA synthesis and real-time quantitative PCR}

Mouse mRNA extraction was performed using the NucleoSpin ${ }_{\circledR}$ RNA II kit (Macherey Nagel, Hoerd, France) on unlavaged frozen left lung. The concentrations and quality of mRNA were determined by spectrophotometry and agarose 


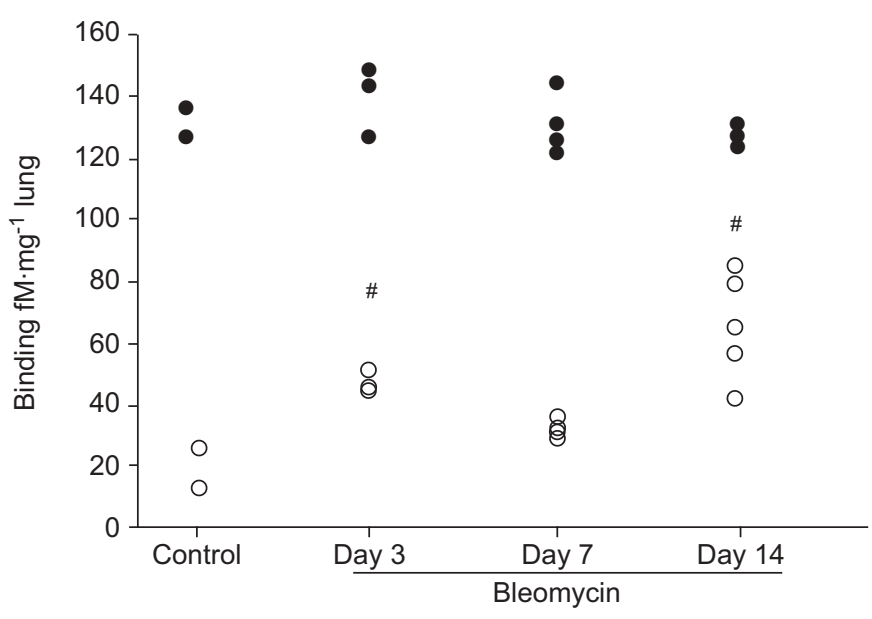

FIGURE 3. Specific binding of serotonin (5-hydroxytryptamine; 5-HT)2A ( and 5 -HT2B $(\bigcirc)$ receptors in bleomycin-induced lung fibrosis. Results are from the azygous and diaphragmatic lobes of the right lung. No variation was observed between controls (naiive mice) and bleomycin-treated lungs for 5-HT2A, whereas there was an increased specific binding for the $5-\mathrm{HT} 2 \mathrm{~B}$ receptor in bleomycintreated lungs compared with controls at days three and 14. At each time-point, three to five animals were used. ${ }^{\#}: p=0.004$ compared with control.

gel electrophoresis. Reverse transcription was performed with random hexamer primers, oligo(d)T and reverse transcriptase MMLV-1 (Promega, Charbonnières, France). Primers for PCR were designed with Primer Express $₫$ software (Applied Biosystems, Courtaboeuf, France) and the following genes were studied: 5-HT2A receptor; 5-HT2B receptor; TGF- $\beta 1$; connective growth factor (CTGF); procollagen 1 ( $\alpha 2$ chain); procollagen 3 ( $\alpha 1$ chain); and plasminogen activator inhibitor (PAI)-1. Hypoxanthine phosphoribosyltransferase (HPRT) served as an endogenous mRNA control. Each amplification reaction was performed in duplicate with SybrGreen mix (Sigma-Aldrich) and specific primers (table 1 in the online supplementary material). Signal detection and analysis of results was performed with $\mathrm{ABI}$ prism 7700 sequence detection software (Applied Biosystems). The expression of the gene of interest was expressed relative to the housekeeping gene, HPRT, as the relative number of copies calculated with a standard curve using $10^{-1}$ to $10^{-4}$ dilutions. A negative water control was used for each primer.

\section{Human lung samples}

Human lung tissue samples obtained from two controls and four idiopathic pulmonary fibrosis (IPF) patients were used for mRNA analysis and immunohistochemistry. Control lung was obtained at the time of surgery for a localised lung tumour from an uninvolved segment. IPF lung tissue was obtained at the time of surgical lung biopsy or transplantation; IPF was diagnosed according to the American Thoracic Society/ European Respiratory Society consensus criteria [14]. The study was approved by the local ethical committee (Comité Consultatif de Protection des Personnes dans la Recherche Biomédicale, St Germain en Laye, France). Informed consent was obtained for all patients. Samples were immediately frozen in liquid nitrogen and stored at $-80^{\circ} \mathrm{C}$ until use. The histopathology of biopsies was evaluated on cryostat sections before their use for immunohistochemical studies.
For immunohistochemical staining, cryostat sections 4-6 $\mu \mathrm{m}$ thick and fixed in acetone were incubated with 5-HT2A and 5-HT2B polyclonal antibodies (Santa Cruz Biotechnology, Inc., Santa Cruz, CA, USA) at room temperature for $1 \mathrm{~h}$ and revealed using the VECTASTAIN ${ }_{\circledast}$ ABC alkaline phosphatase kit system (Vector Labs, Abcys, Paris, France) and the Fast Red substrate (Dako). Normal goat serum (Vector Labs) was used as a control, and no positive cells were identified.

\section{Statistical analysis}

A nonparametric Mann-Whitney U-test was used to compare two groups. Comparisons of data between various treatments groups were performed with a nonparametric Kruskal-Wallis test followed by a Mann-Whitney U-test. Differences between IPF and control fibroblasts were determined by the MannWhitney U-test. Data are expressed as mean \pm SEM. In all tests, a $\mathrm{p}$-value $<0.05$ was considered significant.

\section{RESULTS}

Quantification of serotonin and its receptors in murine lung In order to determine whether the serotonin pathway was involved in the pathogenesis of bleomycin-induced lung fibrosis, the serotonin concentration in lung homogenates was measured and then the expression and localisation of the two main receptors, 5-HT2A and 5-HT2B, were evaluated in the lung.

Serotonin was measured in lung homogenates from control and bleomycin-treated mice on days three, seven and 14. The serotonin concentration increased over the time course of bleomycin-induced fibrosis, with a maximum increase at day seven (increased from $144 \pm 25$ to $310 \pm 18 \mathrm{nM} ; \mathrm{p}=0.008$ ), and was still increased on day $14(274 \pm 51 \mathrm{nM}$; $\mathrm{p}=0.04$; fig. 1$)$. Along with the increase of the serotonin concentration in lung homogenates, increased expression of its receptors, 5-HT2A and 5-HT2B, was observed.

A very low level of 5-HT2A and 5-HT2B mRNA was detected in control lungs by real-time quantitative PCR. After intratracheal bleomycin administration, lung 5-HT2A receptor mRNA content was increased 23-fold at day three $(p=0.002)$, and this high expression was maintained until day 14 (fig. 2a). Similarly, lung 5-HT2B receptor mRNA content was increased 16 -fold at day three compared with controls $(\mathrm{p}=0.001)$, and high expression was maintained until day 14 (fig. 2b).

Binding experiments allowed quantification of the relative availability of 5-HT2A and 5-HT2B receptors in the lung. In the normal lung, 5-HT2A specific binding was six-fold higher than 5-HT2B specific binding. After intratracheal bleomycin administration, 5-HT2A specific binding was unchanged, whereas 5-HT2B specific binding increased six-fold at day three $(p=0.04)$ and was maintained until day 14 (fig. 3).

Immunohistochemical studies allowed localisation of the 5-HT2A and 5-HT2B receptors in lung tissue. In bleomycintreated lungs, the 5-HT2A and 5-HT2B receptors were expressed by bronchial epithelial cells, alveolar macrophages, endothelial cells and peri-arterial smooth muscle cells (figs 4 and 5). In addition, the 5-HT2A receptor was expressed by mesothelial cells (fig. $4 \mathrm{~d}$ ). Over the time course of bleomycin-induced lung fibrosis, the immunostaining of 5-HT2A and 5-HT2B receptors remained unchanged in resident cells, whereas the inflammatory cell infiltrate (polymorphonuclear neutrophils and lymphocytes) 

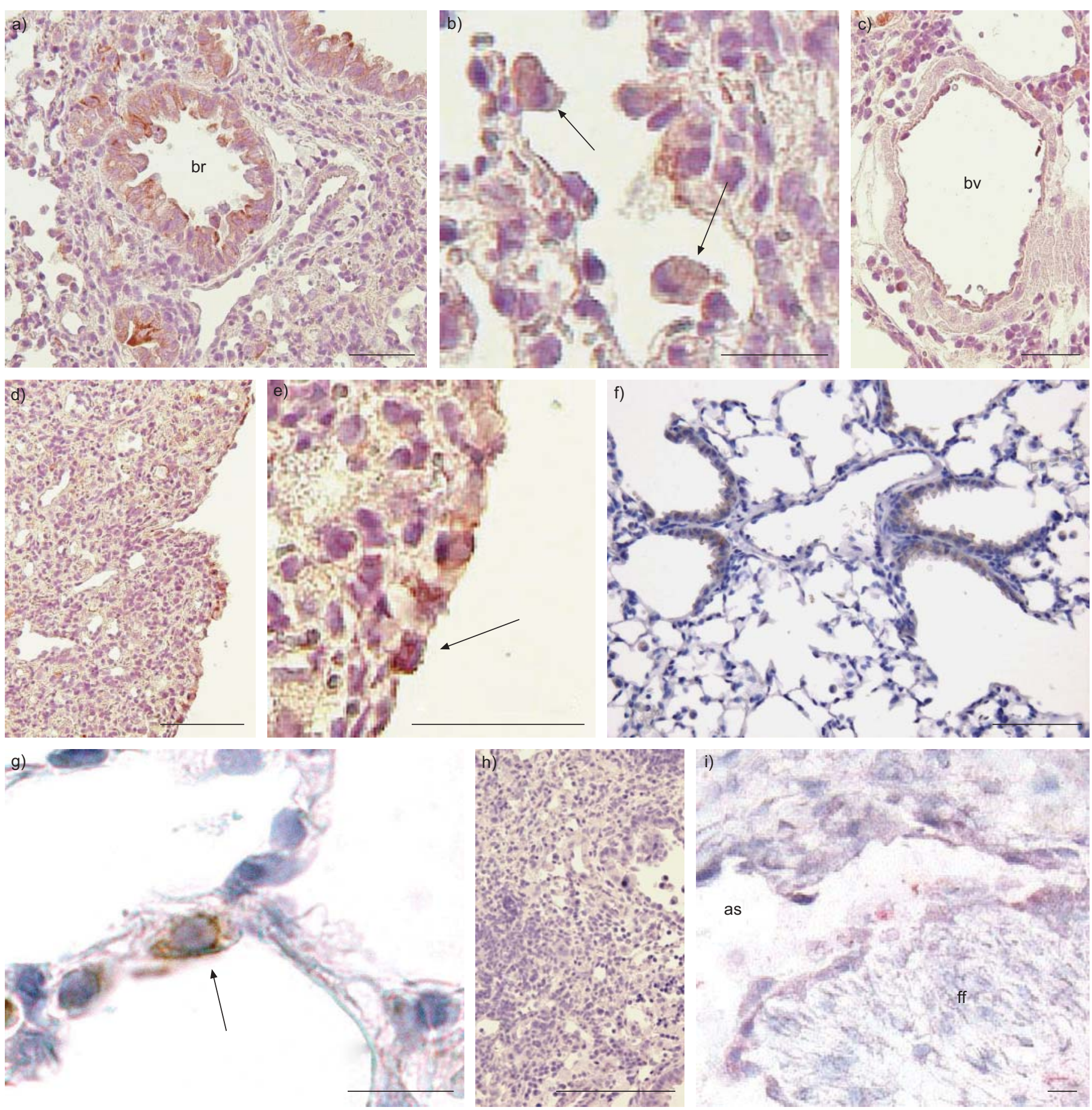

FIGURE 4. Immunohistochemical detection of the serotonin (5-hydroxytryptamine; 5-HT)2A receptor. In bleomycin-treated mouse lungs, the 5-HT2A receptor was expressed by a) bronchial epithelial cells and b) macrophages (arrows), c) weakly by smooth muscle and endothelial cells, and by mesothelial cells lining the pleura (d and e). f) In control murine lungs, 5-HT2A was mainly expressed by bronchial epithelial cells and g) focally by pneumocytes along the alveolar wall. h) Negative control using mouse immunoglobulin G1 shown for comparison. i) Immunohistochemical localisation of the human 5-HT2A receptor in cryosections of lungs from idiopathic pulmonary fibrosis patients, using the VECTASTAIN ABC alkaline phosphatase kit system (Vector Labs, Abcys, Paris, France) and the Fast Red substrate (Dako, Trappes, France), showed expression by hyperplastic type II pneumocytes lining the alveolar space (as), but not in fibroblasts, particularly in the fibroblastic focus (ff). br: bronchiole; bv: blood vessel. $\mathrm{a}-\mathrm{e}, \mathrm{h}$ and i) Scale bars $=100 \mu \mathrm{m}$. $\mathrm{f}$ and g) Scale bars $=50 \mu \mathrm{m}$.

showed positive staining for the 5-HT2B receptor (fig. $5 \mathrm{~d}$ ) but not for 5-HT2A. This parallels the effect of 5-HT2B on the inflammatory cells in BALF (table 2 in the online supplementary material). In control lung, the 5-HT2A and 5-HT2B receptors were mainly expressed by bronchial epithelial cells (figs $4 \mathrm{f}$ and $5 \mathrm{e}$ ), and to a lesser degree by alveolar macrophages and endothelial cells (not shown). Type II pneumocytes also expressed both receptors in control murine lungs (figs $4 \mathrm{~g}$ and $5 \mathrm{f}$ ). 

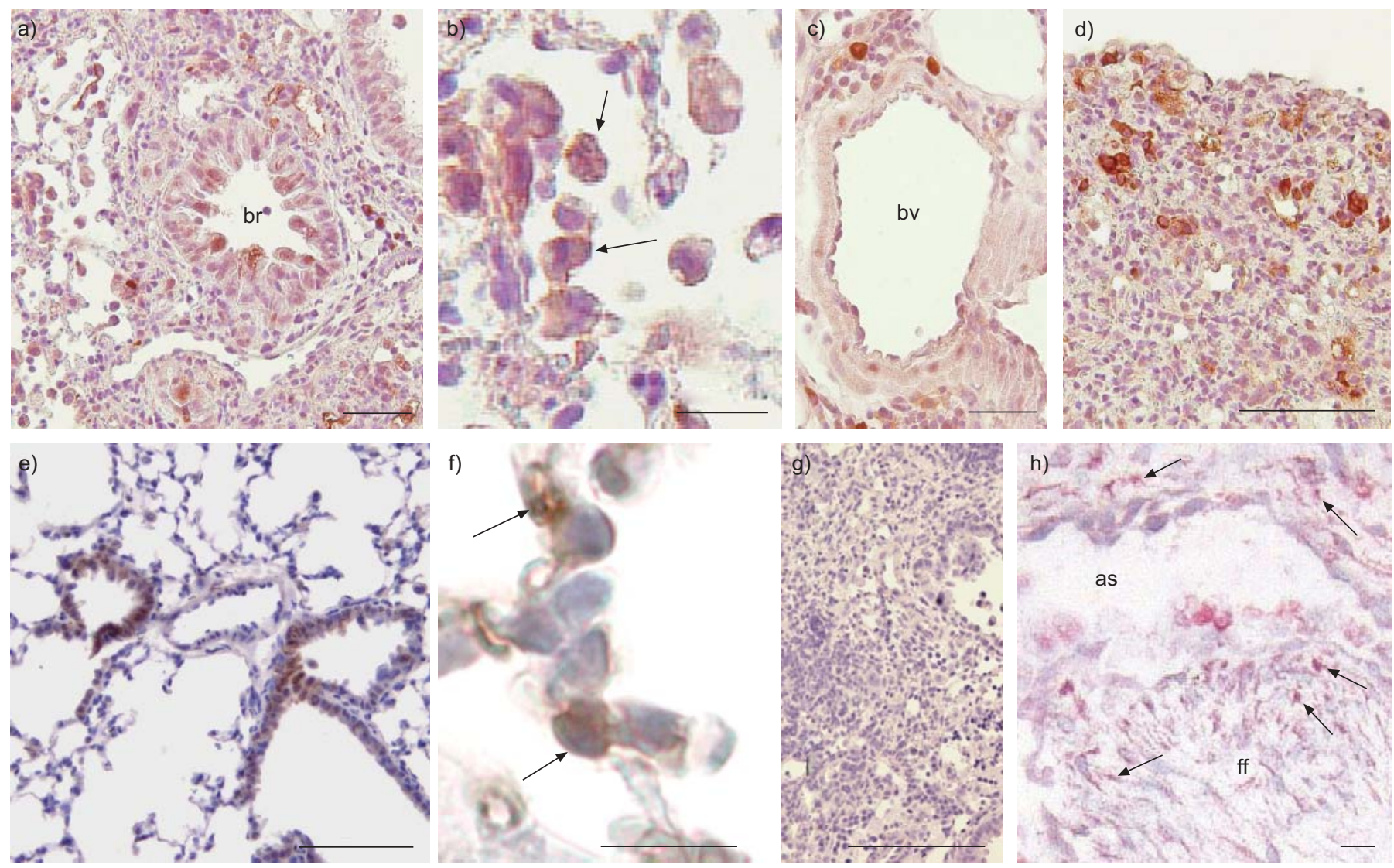

FIGURE 5. Immunohistochemical detection of serotonin (5-hydroxytryptamine; 5-HT)2B receptor. In bleomycin-treated mouse lungs, the 5-HT2B receptor was expressed by a) bronchial epithelial cells and b) alveolar macrophages (arrows), c) weakly by smooth muscle cells and focally by endothelial cells, and d) strongly by inflammatory cells within the lesions (macrophages, lymphocytes and polymorphonuclear cells). Mesothelial cells remained negative for this receptor. e) In control murine lungs, 5-HT2B was mainly expressed by bronchial epithelial cells and f) focally by pneumocytes along the alveolar wall. g) Negative control using mouse immunoglobulin G1 shown for comparison. h) Immunohistochemical localisation of the human 5-HT2B receptor in cryosections of lungs from idiopathic pulmonary fibrosis patients, using the

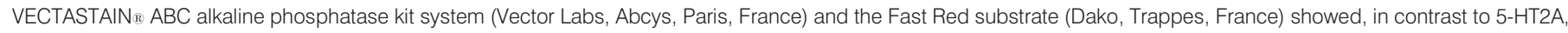
that the 5-HT2B receptor was strongly expressed by fibroblasts in the fibroblastic focus (ff) and in the surrounding fibrotic tissue (arrows), as well as by hyperplastic pneumocytes. br: bronchiole; bv: blood vessel; as: alveolar space. a-d, g and h) Scale bars=100 $\mu \mathrm{m}$. e and f) Scale bars $=50 \mu \mathrm{m}$.

Together, these results demonstrate the expression of 5-HT2A and 5-HT2B receptors in bleomycin-induced lung fibrosis.

\section{Ketanserin and SB215505 reduced lung collagen content}

In preliminary experiments, it was checked that ketanserin and SB215505 at the doses of 2 and $0.5 \mathrm{mg} \cdot \mathrm{kg}^{-1} \cdot \mathrm{day}^{-1}$, respectively, decreased lung $\mathrm{IP}_{3}$ concentration, and that these concentrations were in the plateau of the dose-response curve (fig. 1 in the online supplementary material). The safety of the specific 5-HT2A and 5-HT2B receptor antagonists was assessed by giving daily i.p. injections of ketanserin, SB215505 or the vehicle to naïve mice for 14 days. Stable weight, normal lung histology and normal BAL cytology were observed (data not shown). No mortality was associated with these treatments. In further experiments, the protective effects of ketanserin and SB215505 were evaluated in mice with bleomycin-induced lung fibrosis. A group of animals received the vehicle only.

Intratracheal administration of bleomycin produced a significant increase in lung collagen at day 14 , when compared with salinetreated mice by histological analysis with MT and PS stains (fig. 6). Daily i.p. treatment with ketanserin or SB215505 significantly reduced collagen content (to $86.4 \pm 6.8$ and $97.2 \pm 6 \mu \mathrm{g}$ per right lung, respectively) compared with vehicletreated mice $(116 \pm 6.4 \mu \mathrm{g}$ per right lung; $\mathrm{p}=0.0006$ for both antagonists; fig. $7 \mathrm{a}$ ). Ketanserin significantly reduced procollagen 1 mRNA in lung homogenates by $46 \%(\mathrm{p}=0.02)$ and procollagen $3 \mathrm{mRNA}$ by $44 \%$ ( $\mathrm{p}=0.046)$ compared with vehicle-treated mice at day 14 (fig. $7 \mathrm{~b}$ and c). Similarly, SB215505 reduced procollagen 1 by $31 \%(\mathrm{p}=0.06)$ and procollagen 3 mRNA by $39 \%(\mathrm{p}=0.047)$ compared with the vehicle group (fig. $7 \mathrm{~b}$ and c).

These results demonstrate for the first time an antifibrotic action of specific 5-HT2A and 5-HT2B receptor antagonists in lung fibrosis.

\section{Serotonin antagonists had a minimal effect on alveolar inflammation}

In order to determine whether the protective effect of serotonin antagonists was secondary to an anti-inflammatory effect, BAL cytology was evaluated on days three, seven and 14 after bleomycin administration. Serotonin antagonists did not significantly modify BAL cytology on day three or seven. On day 14, SB215505-treated mice displayed an increased percentage 

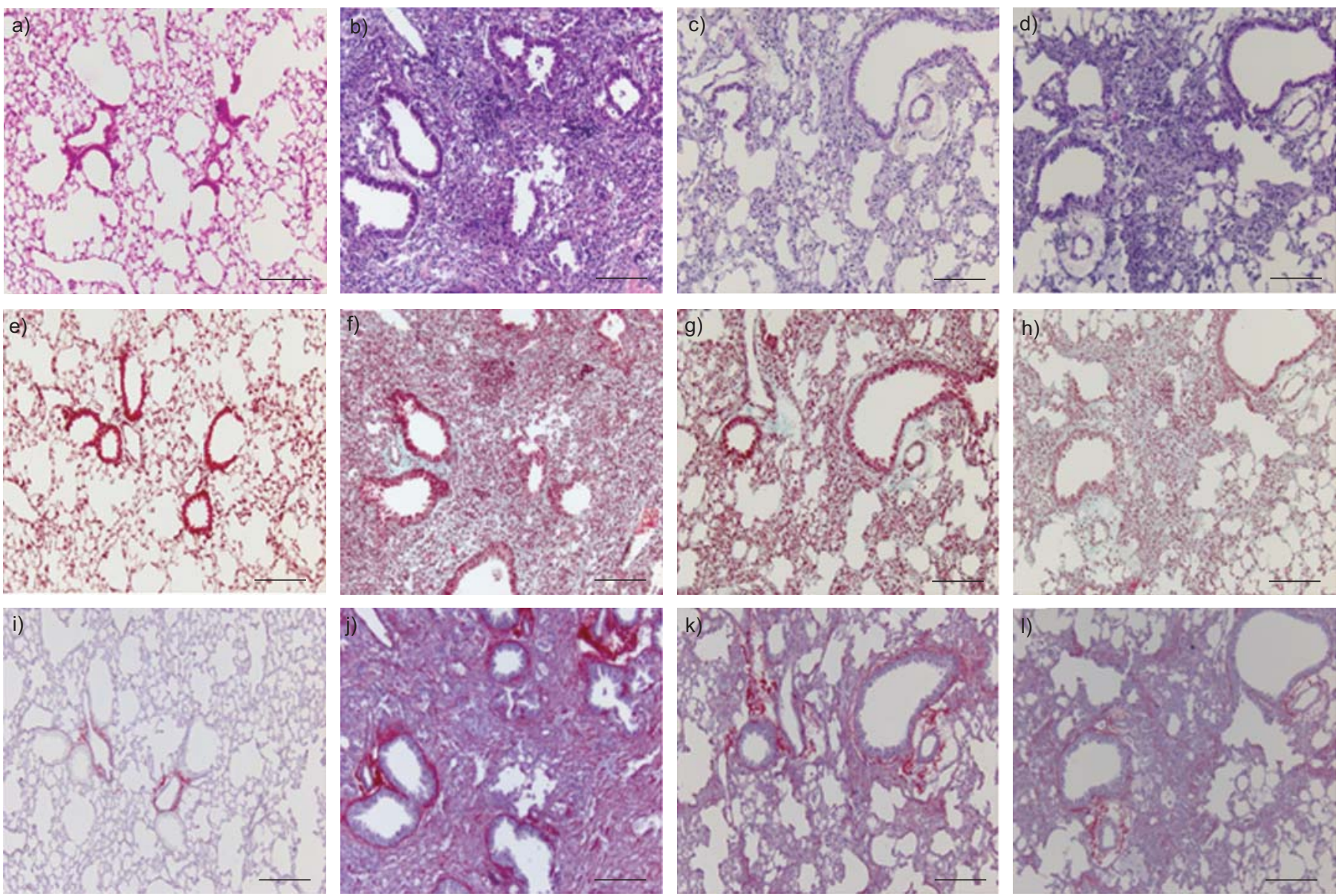

FIGURE 6. The morphological appearance of lung sections stained with haematoxylin-phloxin-saffron (a-d), Masson's trichrome (e-h) and Picrosirius (i-l) showed hardly any collagen deposition in control mice ( $\mathrm{a}$, e and $\mathrm{i}$ ), whereas 14 days post-bleomycin administration there was an increased collagen deposition as demonstrated by extra staining in vehicle-treated mice ( $b, f$ and $j)$, which was clearly less marked in ketanserin- $(c, g$ and $k$ ) and SB215505-treated mice $(d, h$ and I). Scale bars $=100 \mu \mathrm{m}$.

of macrophages $(p=0.019)$ and decreased percentages of neutrophils $(\mathrm{p}=0.02)$ and eosinophils $(\mathrm{p}=0.045)$ compared with vehicle-treated mice, whereas ketanserin had no effect (table 2 in the online supplementary material).

\section{Serotonin antagonists promoted an antifibrotic environment in the lung}

To evaluate the antifibrotic pathway of serotonin, three important factors involved in lung fibrosis were studied: TGF- $\beta 1$, CTGF and PAI-1 [15-17].

As evaluated by quantitative real-time PCR, in vehicle-treated mice, the TGF- $\beta 1$ mRNA content relative to HPRT was increased at day 14 after bleomycin administration when compared with controls $(1.1 \pm 0.008$ versus $0.85 \pm 0.12$, respectively; $\mathrm{p}=0.03$; fig. 8a). Ketanserin and SB215505 decreased the relative lung TGF- $\beta 1$ mRNA content in bleomycin-treated mice from $1.1 \pm 0.008$ for vehicle-treated mice, to $0.77 \pm 0.085(29 \%$ decrease) for ketanserin-treated and $0.72 \pm 0.085$ ( $35 \%$ decrease) for SB215505-treated mice ( $p=0.026$ and $p=0.014$, respectively; fig. $8 \mathrm{a}$ ). The BALF TGF- $\beta 1$ concentration was decreased in mice treated with ketanserin $(p=0.01)$, whereas there was a nonsignificant trend in mice treated with SB215505 (fig. 8b).

Part of the effect of TGF- $\beta 1$ is mediated by CTGF, which also has its own profibrotic effect [18]. While the relative CTGF
mRNA content was increased by $46 \%$ in the fibrotic lungs of vehicle-treated mice compared with naïve controls $(1.71 \pm 0.16$ versus $0.95 \pm 0.13$, respectively; $\mathrm{p}=0.009)$, CTGF mRNA was decreased by $36 \%$ in ketanserin-treated and by $29 \%$ in SB215505-treated mice (to $1.15 \pm 0.16$ and $1.16 \pm 0.21 ; \mathrm{p}=0.017$ and $\mathrm{p}=0.033$, respectively; fig. $8 \mathrm{c}$ ).

PAI-1 is a potent antiproteinase with profibrotic properties in the lung [19]. PAI-1 mRNA was strongly induced in the lung of bleomycin-treated mice compared with controls (relative expression $19 \pm 5.6$ versus $0.49 \pm 0.4$, respectively; $\mathrm{p}=0.0008$; fig. 8d). However, ketanserin and SB215505 profoundly inhibited the PAI-1 increase, and the expression levels, relative to HPRT, were $2.37 \pm 0.51$ and $3 \pm 0.8 \quad(p=0.007$ and $p=0.008$ compared with vehicle-treated mice, respectively; fig. $8 \mathrm{~d}$ ).

Taken in combination, the present results demonstrate that serotonin antagonists induce an antifibrotic environment in the lung by reducing TGF- $\beta 1$, CTGF and PAI-1 expression.

\section{Serotonin receptors 5-HT2A and 5-HT2B were expressed in human lung tissue and fibroblasts}

Immunohistochemical analysis of the 5-HT2A and 5-HT2B receptors was performed on sections from human control and IPF lung samples (figs $4 \mathrm{i}$ and $5 \mathrm{~h}$ ). Both receptors were expressed in the normal and diseased lung. The distribution 

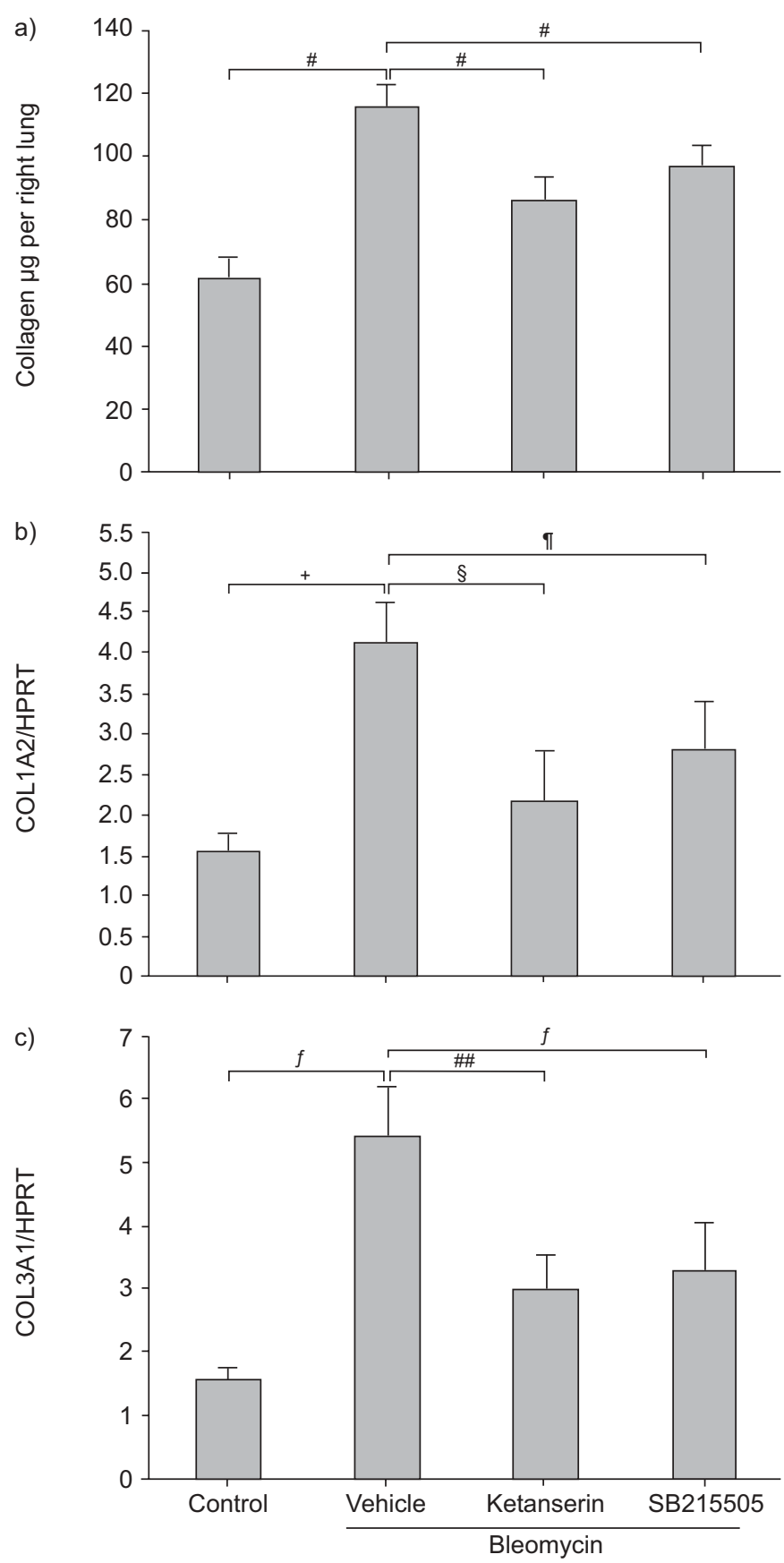

FIGURE 7. a) The total soluble collagen content in the lung, measured by the Sircol $^{\mathrm{TM}}$ assay (Biocolor Ltd, Carrickfergus, UK), was reduced by treatment with ketanserin or SB215505 compared with vehicle-treated mice. Each group contained nine to 11 animals. Expression of b) procollagen 1 (COL1A2) and c) procollagen 3 (COL3A1) assessed by quantitative real-time PCR and expressed relative to the housekeeping gene hypoxanthine phosphoribosyltransferase (HPRT). Ketanserin and SB215505 significantly reduced procollagen 1 and procollagen 3 mRNA at day 14 post-bleomycin administration, compared with vehicle-treated mice. Each group contained 10-11 animals. ${ }^{*}: p=0.0006 ;{ }^{\uparrow}: p=0.06 ;{ }^{+}: p=0.0272 ;{ }^{s}: p=0.02$; $f: p=0.047 ;{ }^{\# \#}: p=0.046$.

of the 5-HT2A receptor was similar in control and IPF lungs. The 5-HT2A receptor was expressed by alveolar macrophages and bronchial epithelial cells, but was not detected in fibroblasts, particularly in the fibroblastic focus (fig. 4i). The 5-HT2B receptor was expressed in control lungs by alveolar macrophages, bronchial epithelial cells and endothelial cells. In IPF lungs, a similar distribution was observed, but strong expression of the 5-HT2B receptor was also demonstrated by fibroblasts in the fibroblastic focus, an area of proliferating fibroblasts located at the leading edge of active fibrosis (fig. 5h), contrasting with the negative staining of 5-HT2A in this area. Interestingly, the 5-HT2B receptor was expressed by fibroblasts in the surrounding fibrotic tissue.

\section{DISCUSSION}

To the current authors' knowledge, this is the first study addressing the serotonin pathway in the pathophysiology of lung fibrosis. Lung serotonin content was increased in bleomycin-induced fibrosis and, in parallel, the expression of the serotonin receptors 5-HT2A and 5-HT2B was increased in the fibrotic lung, as detected by quantitative PCR, binding experiments and immunohistochemical staining. Inhibition of 5-HT2A and 5-HT2B receptors by blocking with specific antagonists promoted an antifibrotic environment in bleomycin-induced lung fibrosis, through the inhibition of key factors involved in lung fibrosis: TGF- $\beta 1$, CTGF and PAI- 1 . In contrast, inflammatory changes observed by BAL cytology were minimal, and only occurred after SB215505 administration. Finally, the expression of 5-HT2A and 5-HT2B receptors in IPF patients was demonstrated, and the specific expression of the 5-HT2B receptor was particularly noted in fibroblasts in the fibroblastic focus characteristic of usual interstitial pneumonia.

Serotonin is a peptide with well-known functions in the lung [20]. Serotonin is synthesised from tryptophan and pooled in platelets, which store and release serotonin via the serotonin transporter 5-HTT. Very low levels of circulating free serotonin are detected in normal conditions. Serotonin is degraded by the monoamine oxidase A. In the lung, the main sources of serotonin include platelets, neuroendocrine cells, mast cells in certain inflammatory and fibrotic conditions [21], and endothelial cells as recently identified $[2,3]$. Serotonin release by these cells may explain the increase in serotonin content following bleomycin-induced lung fibrosis that was observed in the present study. Mast cell numbers are increased in the fibrotic lung [22] and may release serotonin under certain stimuli [23]. In addition, neuroendocrine cell numbers are increased in human IPF lung samples [24] and platelets have been associated with lung fibrosis and may be considered as a profibrotic factor [25]. Finally, endothelial cells are recognised as cellular targets in pulmonary fibrosis [26].

The present study concentrated on 5-HT2A and 5-HT2B receptors in lung fibrosis, since these receptors have been shown to play an important role in lung pathophysiology [27] and to have profibrotic properties in respiratory $[5,6]$ and nonrespiratory tissues $[8,28]$. The demonstration of 5-HT2A and 5-HT2B receptor expression in the lung vessels, including endothelial cells and peri-arterial smooth muscle cells, agrees with previous data [5, 6]. Type-II pneumocytes, epithelial bronchial cells, pleural mesothelial cells and lung fibroblasts have also been shown in the present study to express 5-HT2A and 5-HT2B receptors in normal and fibrotic lungs. Thus, the serotonin pathway appears to act on many different cell types potentially involved in the pathogenesis of lung fibrosis. The 

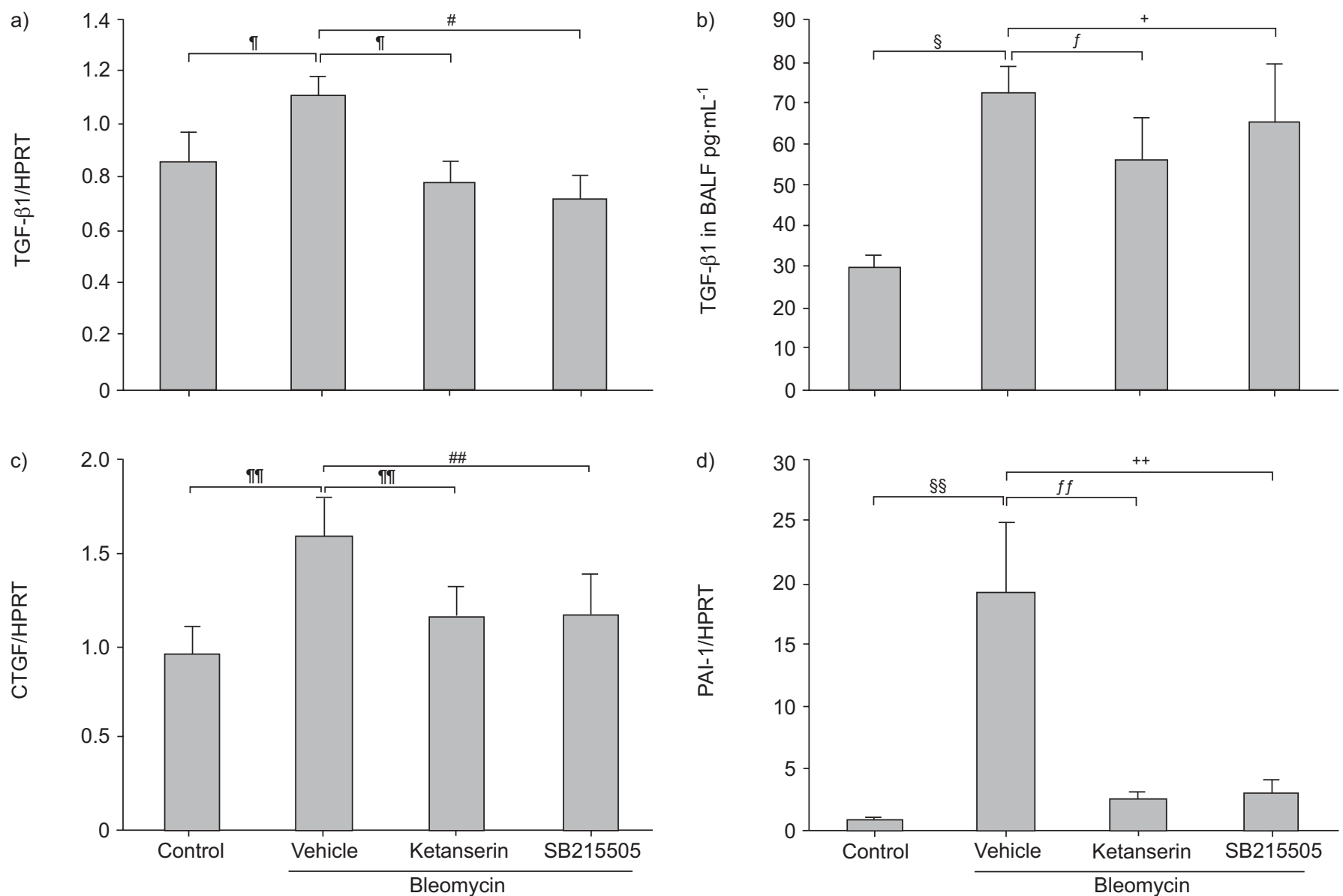

FIGURE 8. Inhibition of profibrotic mediators by serotonin (5-hydroxytryptamine; 5-HT)2A and 5-HT2B receptor antagonists. a) Transforming growth factor (TGF)- $\beta 1$ mRNA in lung homogenates, expressed relative to the housekeeping gene hypoxanthine phosphoribosyltransferase (HPRT), was reduced following treatment with ketanserin and SB215505 at day 14 post-bleomycin administration. b) The TGF- $\beta 1$ concentration in bronchoalveolar lavage fluid (BALF), measured by ELISA, was reduced after treatment with ketanserin, compared with vehicle-treated mice. A trend towards reduction was observed for SB215505. c) The connective growth factor (CTGF) mRNA content was increased in the fibrotic lungs of vehicle-treated mice compared with naïve controls, but decreased in mice treated with ketanserin and SB215505 compared with vehicletreated mice. d) Plasminogen activator inhibitor (PAl)-1 mRNA was markedly reduced following treatment with ketanserin and SB215505, compared with vehicle-treated mice.

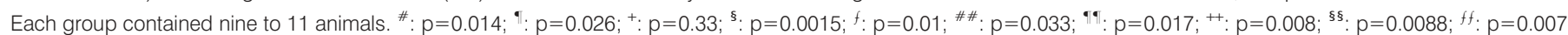

expression of 5-HT2B by fibroblasts in human tissue sampled from IPF lungs, especially in the fibroblastic focus (which is thought to be the site of active fibrosis) puts into perspective the results in the mouse model of lung fibrosis.

Lung expression of 5-HT2A and 5-HT2B mRNA was observed to be markedly increased after bleomycin administration. However, specific 5-HT2A binding did not change, while 5-HT2B binding increased significantly at days three, seven and 14. This suggests that the regulation of expression of the 5-HT2A and 5-HT2B receptors is different, and that posttranscriptional regulation plays a key role for both receptors in vivo.

In addition, immunohistochemical studies indicated that both resident cells and inflammatory cells expressed 5-HT2A and 5-HT2B serotonin receptors in the lung (figs 4 and 5). Immunohistochemistry does not allow a quantitative analysis of the level of expression of the receptors in each cell. Since there was a marked inflammatory infiltrate in the initial phase of bleomycin-induced lung disease, the current authors suspect that the increased expression of 5-HT2A and 5-HT2B receptors was due to the combination of inflammatory cell infiltration and increased expression on a per cell basis.

Blocking of 5-HT2A and 5-HT2B receptors by specific antagonists (ketanserin and SB215505, respectively) supported previous published data on the profibrotic properties of serotonin [7, 8]. In the bleomycin mouse model of lung fibrosis used in the present study, daily i.p. administration of ketanserin and SB215505 significantly reduced collagen content and procollagen 1 and 3 expression, which were previously shown to be selectively increased in this model of lung fibrosis [29]. The antifibrotic effect observed following treatment with ketanserin and SB215505 to selectively block 5-HT2A and 5-HT2B receptors appears to be associated with changes in the expression of the potent key profibrotic factors TGF- $\beta 1$, CTGF and PAI- 1 . These factors have previously been linked to serotonin, 5-HT2A and 5-HT2B receptor activation in other experimental settings. Indeed, upregulation of the TGF$\beta 1$ pathway by serotonin via its $5-\mathrm{HT} 2 \mathrm{~A}$ receptor has been previously described in cultured mesangial cells [28], and also 
demonstrated in aortic valve interstitial cells cultured from aortic valve [10]. Expression of CTGF is induced in renal mesangial cells by serotonin [30]. Finally, PAI-1 displays a close relationship with the serotoninergic systems, as in vitro serotonin increases PAI-1 expression by rat aortic endothelial cells [31].

In conclusion, the present study has demonstrated the antifibrotic effect of specific serotonin 5-HT2A and 5-HT2B receptor antagonists in vivo using the animal model of bleomycin-induced lung fibrosis, and the involvement of the transforming growth factor- $\beta 1$, connective growth factor and plasminogen activator inhibitor-1 pathways. The observations in human samples support the hypothesis that the serotonin pathway might be involved in the pathophysiology of human lung fibrosis. Treatment with specific antagonists of targeted receptors may offer a new therapeutic approach in humans, which needs to be assessed in further studies.

\section{ACKNOWLEDGEMENTS}

The authors would like to thank O. Thibaudeau from the Morphology Department of the Bichat Institute of Research (Paris, France) and the technicians of the Pathology Department of Bichat Hospital (Paris) for technical assistance.

\section{REFERENCES}

1 King TE Jr. Clinical advances in the diagnosis and therapy of the interstitial lung diseases. Am J Respir Crit Care Med 2005; 172: 268-279.

2 Eddahibi S, Guignabert C, Barlier-Mur AM, et al. Cross talk between endothelial and smooth muscle cells in pulmonary hypertension: critical role for serotonin-induced smooth muscle hyperplasia. Circulation 2006; 113: 1857-1864.

3 Sullivan CC, Du L, Chu D, et al. Induction of pulmonary hypertension by an angiopoietin 1/TIE2/serotonin pathway. Proc Natl Acad Sci USA 2003; 100: 12331-12336.

4 Richter DW, Manzke T, Wilken B, Ponimaskin E. Serotonin receptors: guardians of stable breathing. Trends Mol Med 2003; 9: 542-548.

5 Marcos E, Fadel E, Sanchez O, et al. Serotonin-induced smooth muscle hyperplasia in various forms of human pulmonary hypertension. Circ Res 2004; 94: 1263-1270.

6 Loric S, Maroteaux L, Kellermann O, Launay JM. Functional serotonin-2B receptors are expressed by a teratocarcinoma-derived cell line during serotoninergic differentiation. Mol Pharmacol 1995; 47: 458-466.

7 Welsh DJ, Harnett M, MacLean M, Peacock AJ. Proliferation and signaling in fibroblasts: role of 5hydroxytryptamine2A receptor and transporter. Am J Respir Crit Care Med 2004; 170: 252-259.

8 Ruddell RG, Oakley F, Hussain Z, et al. A role for serotonin (5-HT) in hepatic stellate cell function and liver fibrosis. Am J Pathol 2006; 169: 861-876.

9 Grewal JS, Mukhin YV, Garnovskaya MN, Raymond JR, Greene EL. Serotonin 5-HT2A receptor induces TGF- $\beta 1$ expression in mesangial cells via ERK: proliferative and fibrotic signals. Am J Physiol 1999; 276: F922-F930.

10 Jian B, Xu J, Connolly J, et al. Serotonin mechanisms in heart valve disease I: serotonin-induced up-regulation of transforming growth factor- $\beta 1$ via G-protein signal transduction in aortic valve interstitial cells. Am J Pathol 2002; 161: 2111-2121.

$11 \mathrm{Xu} \mathrm{J}$, Jian B, Chu R, et al. Serotonin mechanisms in heart valve disease II: the 5-HT2 receptor and its signaling pathway in aortic valve interstitial cells. Am J Pathol 2002; 161: 2209-2218.

12 Esteve JM, Launay JM, Kellermann O, Maroteaux L. Functions of serotonin in hypoxic pulmonary vascular remodeling. Cell Biochem Biophys 2007; 47: 33-44.

13 Alvarez JC, Gluck N, Arnulf I, et al. Decreased platelet serotonin transporter sites and increased platelet inositol triphosphate levels in patients with unipolar depression: effects of clomipramine and fluoxetine. Clin Pharmacol Ther 1999; 66: 617-624.

14 American Thoracic Society, European Respiratory Society. American Thoracic Society/European Respiratory Society International Multidisciplinary Consensus Classification of the Idiopathic Interstitial Pneumonias. This joint statement of the American Thoracic Society (ATS), and the European Respiratory Society (ERS) was adopted by the ATS board of directors, June 2001 and by the ERS Executive Committee, June 2001. Am J Respir Crit Care Med 2002; 165: 277-304.

15 Lasky JA, Ortiz LA, Tonthat B, et al. Connective tissue growth factor mRNA expression is upregulated in bleomycin-induced lung fibrosis. Am J Physiol 1998; 275: L365-L371.

16 Chuang-Tsai S, Sisson TH, Hattori N, et al. Reduction in fibrotic tissue formation in mice genetically deficient in plasminogen activator inhibitor-1. Am J Pathol 2003; 163: 445-452.

17 Bartram U, Speer CP. The role of transforming growth factor $\beta$ in lung development and disease. Chest 2004; 125: 754-765.

18 Bonniaud P, Martin G, Margetts PJ, et al. Connective tissue growth factor is crucial to inducing a profibrotic environment in "fibrosis-resistant" BALB/c mouse lungs. Am J Respir Cell Mol Biol 2004; 31: 510-516.

19 Kucharewicz I, Kowal K, Buczko W, Bodzenta-Łukaszyk A. The plasmin system in airway remodeling. Thromb Res 2003; 112: 1-7.

20 de Caestecker M. Serotonin signaling in pulmonary hypertension. Circ Res 2006; 98: 1229-1231.

21 Franko AJ, Sharplin J. Development of fibrosis after lung irradiation in relation to inflammation and lung function in a mouse strain prone to fibrosis. Radiat Res 1994; 140: 347-355.

22 Chyczewski L, Debek W, Chyczewska E, Debek K, Bankowski E. Morphology of lung mast cells in rats treated with bleomycin. Exp Toxicol Pathol 1996; 48: 515-517.

23 Yong LC. The mast cell: origin, morphology, distribution, and function. Exp Toxicol Pathol 1997; 49: 409-424.

24 Ito T, Ogura T, Ogawa N, et al. Modulation of pulmonary neuroendocrine cells in idiopathic interstitial pneumonia. Histol Histopathol 2002; 17: 1121-1127.

25 Piguet PF, Vesin C. Pulmonary platelet trapping induced by bleomycin: correlation with fibrosis and involvement of the $\beta 2$ integrins. Int J Exp Pathol 1994; 75: 321-328.

26 Magro CM, Waldman WJ, Knight DA, et al. Idiopathic pulmonary fibrosis related to endothelial injury and antiendothelial cell antibodies. Hum Immunol 2006; 67: 284-297. 
27 Shi W, Wang CG, Dandurand RJ, Eidelman DH, Michel RP. Differential responses of pulmonary arteries and veins to histamine and 5-HT in lung explants of guinea-pigs. $\mathrm{Br} \mathrm{J}$ Pharmacol 1998; 123: 1525-1532.

28 Greene EL, Houghton O, Collinsworth G, et al. 5-HT2A receptors stimulate mitogen-activated protein kinase via $\mathrm{H}_{2} \mathrm{O}_{2}$ generation in rat renal mesangial cells. Am J Physiol Renal Physiol 2000; 278: F650-F658.

29 Hesterberg TW, Gerriets JE, Reiser KM, Jackson AC, Cross CE, Last JA. Bleomycin-induced pulmonary fibrosis: correlation of biochemical, physiological, and histological changes. Toxicol Appl Pharmacol 1981; 60: 360-367.

30 Hahn A, Heusinger-Ribeiro J, Lanz T, Zenkel S, GoppeltStruebe M. Induction of connective tissue growth factor by activation of heptahelical receptors. Modulation by Rho proteins and the actin cytoskeleton. J Biol Chem 2000; 275: 37429-37435.

31 Kawano H, Tsuji H, Nishimura $\mathrm{H}$, et al. Serotonin induces the expression of tissue factor and plasminogen activator inhibitor-1 in cultured rat aortic endothelial cells. Blood 2001; 97: 1697-1702. 